\title{
A Fundamental Study on Vacuum Lift Refining of Molten Copper*
}

\author{
By Hiroshi Kametani** and Chikabumi Yamauchi**
}

\begin{abstract}
Experiments of vacuum lift refining of molten blister copper have been carried out using a copper sample of about $600 \mathrm{~g}$ for a concurrent elimination of residual oxygen, sulphur and impurities.

The volume of liberated $\mathrm{SO}_{2}$ gas was measured by the pressure change in five vacuum reservior tanks connected in turn with the vacuum vessel of about $1.6 \mathrm{~cm}$ ID made of a transparent quartz tube.

An oxygen concentration cell using a calcia stabilized zirconia or a small crystal microphone was equipped inside the vacuum vessel so as to permit the continuous measurement of oxygen potential or the detection of evolution of gas bubbles in the lifted melt.

The present process of overblowing of blister copper in a converter and of the subsequent reduction to refined blister copper in a refining furnace and the vacuum refining process of blister copper were discussed and compared in terms of an equilibrium diagram representing the functional relation among dissolved oxygen, $\log (\% 0)$, dissolved sulphur, $\log (\% \mathrm{~S})$, and the partial pressure of $\mathrm{SO}_{2}$.

Initial concentrations of oxygen and sulphur, 0.130 and $0.107 \%$, were decreased to $0.030 \%$ for oxygen and $0.006 \%$ for sulphur after vacuum lifts of 4 times each at an average pressure of about $2 \mathrm{mmHg}$. Other impurities in synthetic blister copper were also removed : 40 to $70 \%$ of $\mathrm{Sb}, 30$ to $60 \%$ of $\mathrm{Pb}$, and about $10 \%$ of As for initial concentrations of $0.4,0.25$ and $0.4 \%$ at reduced pressures of a few $\mathrm{mmHg}$, respectively.

(Received June 17, 1971)
\end{abstract}

\section{Introduction}

Blister copper produced during the copper making stage in a converter contains residual sulphur and several impurities, such as $\mathrm{Pb}, \mathrm{Sb}, \mathrm{Bi}$, and $\mathrm{As}$. Some of them are eliminated by the subsequent overblowing stage, where the oxygen content in molten copper increases up to about $0.8 \%$ as a result of the oxidation. The oxygen in the melt is then removed in the following refining furnace by a reduction process by wooden pole, pulverized coal, natural gas or ammonia.

The oxygen in molten blister copper can also be eliminated, when the melt contains a proper amount of dissolved sulphur as $\mathrm{SO}_{2}$ gas under reduced pressures. It follows that the impurities in the melt might be simultaneously removed by the gas liberated in the melt, because of their high partial pressures at high operating temperatures.

Most of investigations of molten copper under reduced pressures have been performed for the purpose of determining the thermodynamic values concerning activities of minor solutes dissolved in the melt under equilibrium conditions, and a few studies have been made to determine the elimination of impurities under stagnant conditions $^{(1)}$.

The vacuum degassing of molten steel has already been operated on an industrial scale, e.g. the $\mathrm{D}-\mathrm{H}$ process and the R-H process, but little has been known about vacuum lift refining of molten copper.

This paper presents the fundamentals of the vacuum lift refining process which is carried out using a batchwise vacuum lift apparatus and attendant measurements, that is, the oxygen partial pressure measurement

\footnotetext{
* Vacuum Lift Refining Processes in Copper Smelting, 1st Report.

** National Research Institute for Metals, Nakameguro, Tokyo, Japan.
}

and number counting of liberated $\mathrm{SO}_{2}$ gas bubbles during the refining.

\section{Experimental}

\section{Apparatus}

The vacuum lift apparatus used in this study consists of a resistance electric furnace to melt a copper sample, a vacuum-lift part, a vacuum system part, and accessory measuring parts as illustrated in Figs. 1, 2, and 3. A vertical furnace of $2.4 \mathrm{~cm}$ ID and $100 \mathrm{~cm}$ length was installed so as to permit to slide up and down along vertical rails fixed at a frame. A connecting furnace of $32 \mathrm{~cm}$ length was attached to the lower end of the vertical furnace to make the temperature distribution uniform within the range from $1150^{\circ}$ to $1200^{\circ} \mathrm{C}$ for the whole length from the bottom of a crucible up to the upper end of the vertical furnace, when the vertical furnace was lowered and the lower half of the connecting furnace was inserted into the resistance furnace. A transparent quartz tube vessel, Fig. 2, in which molten copper was sucked up to the hydrostatic height of $130 \mathrm{~cm}$ by the pressure difference between the inside of the evacuated vessel and the outside atmosphere, was set vertically in the vertical furnace. The upper part of the vessel out of the vertical furnace was cooled by a fan. The lower end of the vessel was closed for degassing of the vessel prior to a run. To protect the vessel from damages by slag formation at the surface of the melt, the lower end of the vessel was made in double tubing for a length of $15 \mathrm{~cm}$.

The vacuum system part consists of a rotary vacuum pump, a mercury diffusion pump, 5 vacuum reservior glass tanks of $2.5 \mathrm{~L}$ each, a mercury manometer, and a

(1) M. Kameda and A. Yazawa : Bull. Res. Inst. Min. Dress. Met. Tohoku Univ. Japan, 19(1963), 58.

1972 Vol. 13 


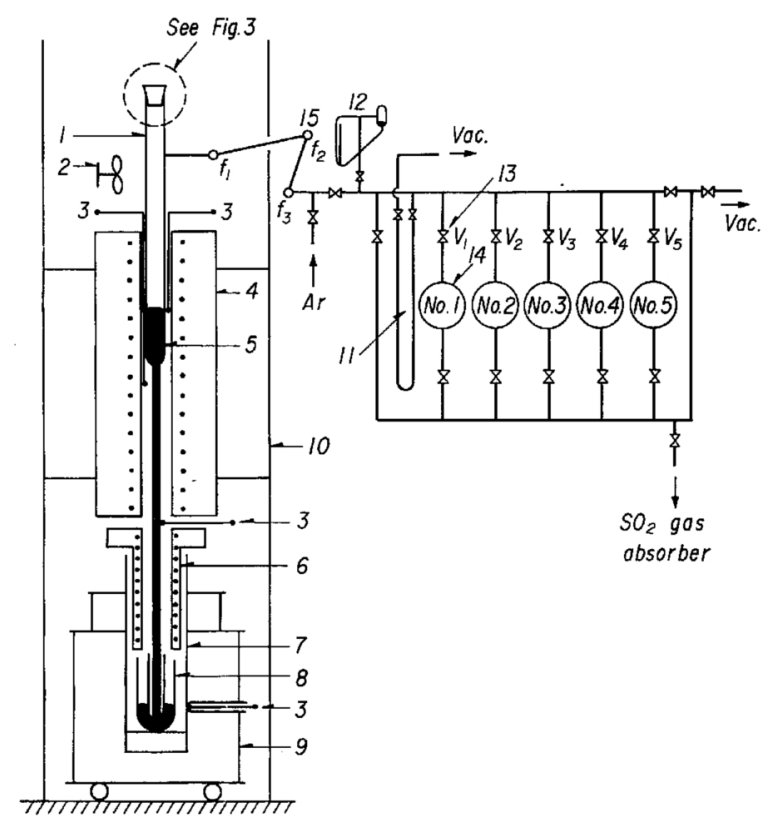

Fig.1 Vacuum lift apparatus.

1 : Transparent quartz tube vacuum vessel $2:$ Fan $3:$ Thermocouples $4:$ Vertical furnace $5:$ Lifted molten copper 6 : Connecting furnace 7 : Silica vessel 8 : Alumina crucible 9 : Resistance electric furnace 10: Vertical guide rail and frame 11 : Mercury manometer $12:$ MacLeod gauge $13: V_{1}$ to $V_{5}$ Stopcocks $14:$ No. 1 to No. 5 Vacuum reservior glass tanks $15: f_{1}$ to $f_{3}$ Bulb joints

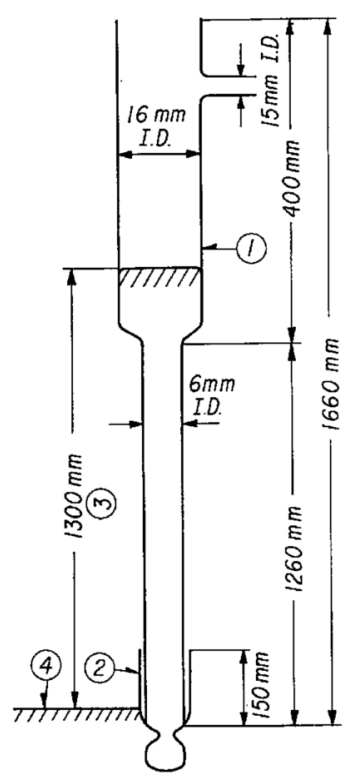

Fig. 2 Vacuum vessel.

1 : Transparent quartz tube vacuum vessel

2 : Opaque quartz tube

3 : Hydrostatic height of molten copper lifted by the pressure difference between the inside of the evacuated vessel and the outside atmosphere

4 : Surface of molten copper in the crucible

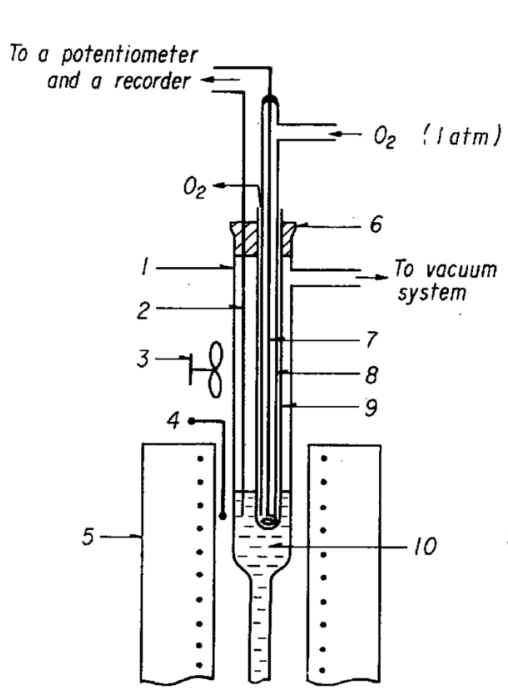

(a)

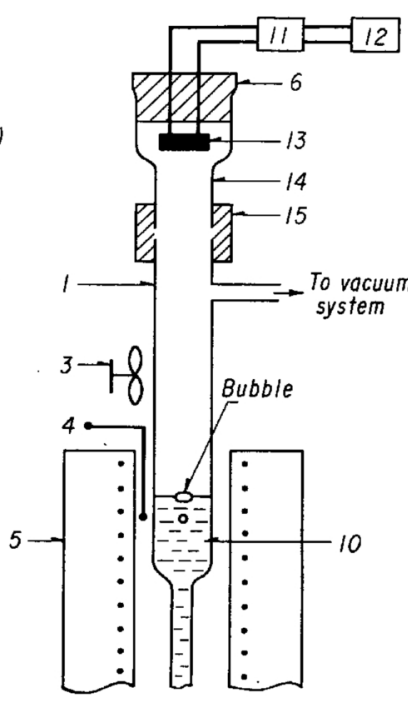

(b)
Fig. 3 Attendant measuring apparatus. 1 : Transparent quartz tube vacuum vessel 2 : Mo lead wire $3:$ Fan 4: Thermocouple $5:$ Vertical furnace $6:$ Rubber stopper $\quad 7:$ Pt lead wire $8:$ Silica tube $9: \mathrm{ZrO}_{2} \cdot \mathrm{CaO}$ tube $10:$ Lifted molten copper 11 : Amplifier $12:$ Recorder $13:$ Crystal microphone 14: Glass tube $15:$ Rubber tube (a): Attachment for oxygen potential measurement

(b) : Attachment for number counting of bubbles
MacLeod gauge as shown in Fig. 1.

The oxygen potential measurement was carried out using an oxygen concentration cell consisting of $\mathrm{O}_{2}$ (1 atm) : $\mathrm{Pt} \mid$ calcia stabilized $\mathrm{ZrO}_{2} \mid$ dissolved $\mathrm{O}$ in melt $\mid$ Mo as shown in Fig. 3 (A). The potential between $\mathrm{Pt}$ and Mo electrodes was previously calibrated by pure copper melts containing known amounts of dissolved oxygen by the aid of a potentiometer at $1200^{\circ} \mathrm{C}$. The potential was continuously measured during a run with a $\mathrm{mV}$-meter of high input resistance $(20 \mathrm{M} \Omega)$ and a recorder. The oxygen concentration was calculated from the potential value according to the empirical equation :

$$
E(V)=0.315-0.144 \log (\% 0)
$$

which is in good agreement with the result reported by Pluschkell and Engell ${ }^{(2)}$.

Equation ( 1 ) is considered to be valid for the melts containing sulphur below $0.2 \mathrm{wt} \%$, because $P_{\mathrm{O}_{2}}$ is nearly independent of the low sulphur content as shown in Fig. 11.

The number counting of bubbles was made using a small crystal microphone which was set in a glass tube attached to the top of the vacuum vessel as shown in Fig. 3(B). A small hole was made on the Al foil

(2) W. Pluschkell and H. J. Engell : Z. Metallk., 56 (1965), 450. 
diaphragm of the microphone to avoid its destruction during rapid changes of pressure. The attenuating vibration due to the burst of a bubble at the surface of the melt was amplified and recorded at a speed of $2 \mathrm{~cm} /$ min. The number of vibrating waves corresponds to the number of bubbles and the maximum amplitude of a wave shows quantitatively the size of a bubble.

\section{Procedure}

Prior to a run of refining, a quartz vessel was placed in the vertical furnace and the connecting furnace, and the temperature was raised to an operating temperature between $1150^{\circ}$ and $1200^{\circ} \mathrm{C}$. The vessel, the bottom of which was sealed, was connected to the vacuum system and degassed for $5 \mathrm{hr}$ at about $10^{-4} \mathrm{mmHg}$. After introducing argon gas in the vessel, the withering part was cut off to open the lower end of the vessel after the pressure became normal. The argon gas was flown into the vessel until the lower end was dipped in the melt and the run started.

Weighed amounts of solid impurities, i.e., mixtures of copper powder and copper sulfide, copper oxide, antimony powder, etc. were packed in drilled holes which were made on the outside of an electrolytic copper block of about $600 \mathrm{~g}$. The copper block was placed in an alumina crucible in the resistance furnace. After the block was melted, $\mathrm{SO}_{2}$ gas was blown into the melt for a specified time ( 5 to $20 \mathrm{~min}$ ) for homogenization of the melt and final adjustments of sulphur and oxygen contents.

The final preparation was made in the order illustrated in Fig. 4. The vertical furnace was preheated at position $B$ and the sample was melted in the resistance furnace at position A. After sampling of the melt by suction with a silica tube, the resistance furnace was moved to position $\mathrm{C}$ directly below the vertical furnace. When the vertical furnace was lowered to position $D$, the Ar flow was stopped and then the vacuum vessel was lowered. The distance between the lower end of the vessel and the bottom of the crucible, ca. $1 \mathrm{~cm}$, was

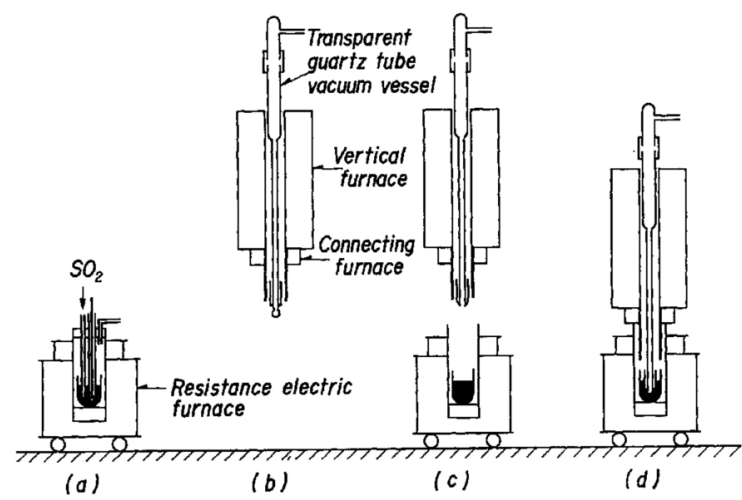

Fig. 4 Setting of each furnace and transparent quartz tube vacuum vessel.

(a) $\mathrm{SO}_{2}$ gas blowing and final adjustment of sulphur and oxygen contents

(b) Preheating of the vertical and the connecting furnaces

(c) Movement of the resistance furnace

(d) Connection of the resistance furnace with the vertical furnace through the connecting furnace checked and the preparation for refining was completed.

With reference to Fig. 1, stopcock $V_{1}$ was first opened and the vessel was connected to the vacuum reservior tank No. 1. The pressure of the vessel decreased to a value around $20 \sim 70 \mathrm{mmHg}$ within $3 \mathrm{~min}$. Generally the degassing was not observed in this step. After closing stopcock $V_{1}, V_{2}$ was opened and the vessel was connected to tank No. 2. The pressure decreased again to a value around $1 \sim 10 \mathrm{mmHg}$, at which $\mathrm{SO}_{2}$ gas bubbling began to take place. Violent bubbling was frequently observed when the concentrations of dissolved $\mathrm{S}$ and $\mathrm{O}$ in the melt were high, and the run was of ten interrupted owing to blow-up of the melt up to the top of the quartz tube. After the initial bubbling became quiet, the pressure was measured and the stopcock was closed. The vessel was then connected to tank No. 3 through $\mathrm{V}_{3}$. The change of pressure was measured at intervals of 5 or $10 \mathrm{~min}$ for a period of $15 \mathrm{~min}$ or more. The vessel was connected to tank No. 4 and then to tank No. 5 in turn. At the end of a run the sucked melt in the vessel was cooled in situ, and samples of refined copper were taken at intervals of a proper length from the solidified copper rod.

The liberated $\mathrm{SO}_{2}$ gas stored in the tanks was expelled by argon gas after a run, absorbed by $\mathrm{N} / 5 \mathrm{NaOH}$ solution, and determined by titration with $\mathrm{N} / 5 \mathrm{HCl}$ or by weighing as $\mathrm{BaSO}_{4}$ after oxidation and precipitation. The volume of the liberated $\mathrm{SO}_{2}$ gas in $\mathrm{mL}$ in S.T.P. calculated from the pressure change and the volume of vacuum tanks plus the dead space of pipings coincided within a difference of $10 \%$ with the volume obtained by chemical analysis.

The procedure of repeating refining was the same as in the first half of the procedure described above. While a tank was used to measure the change of pressure, the other tanks used were connected in turn to a mercury diffusion pump to reuse them again as vacuum tanks. All stopcocks of the vacuum tanks were closed at proper intervals of refining and argon gas was introduced. By the pressure of argon gas raised up to the atmospheric pressure, the sucked content in the vessel was lowered to the crucible. The subsequent refining was made in the same procedure as mentioned above, except the difference in the number of stopcocks and tanks.

\section{Experimental results}

Most of experiments were carried out at the initial oxygen and/or sulphur concentrations lower than $0.2 \%$, owing to violent bubbling at the start of refining. At the initial concentration higher than $0.2 \%$ the run was often interrupted even at a very slow reducing rate of pressure, provided that the inner diameter of the vacuum vessel was as small as $1.6 \mathrm{~cm}$.

\section{(1) Pressure change and liberated gas volume}

Examples of the pressure change and the calculated volume of liberated $\mathrm{SO}_{2}$ gas in S.T.P. with time are illustrated in Figs. 5 and 6, respectively. The region with an abrupt increase of bubbling in these figures is due to the burst of bubbles generated in the melt (see Fig. 9). 


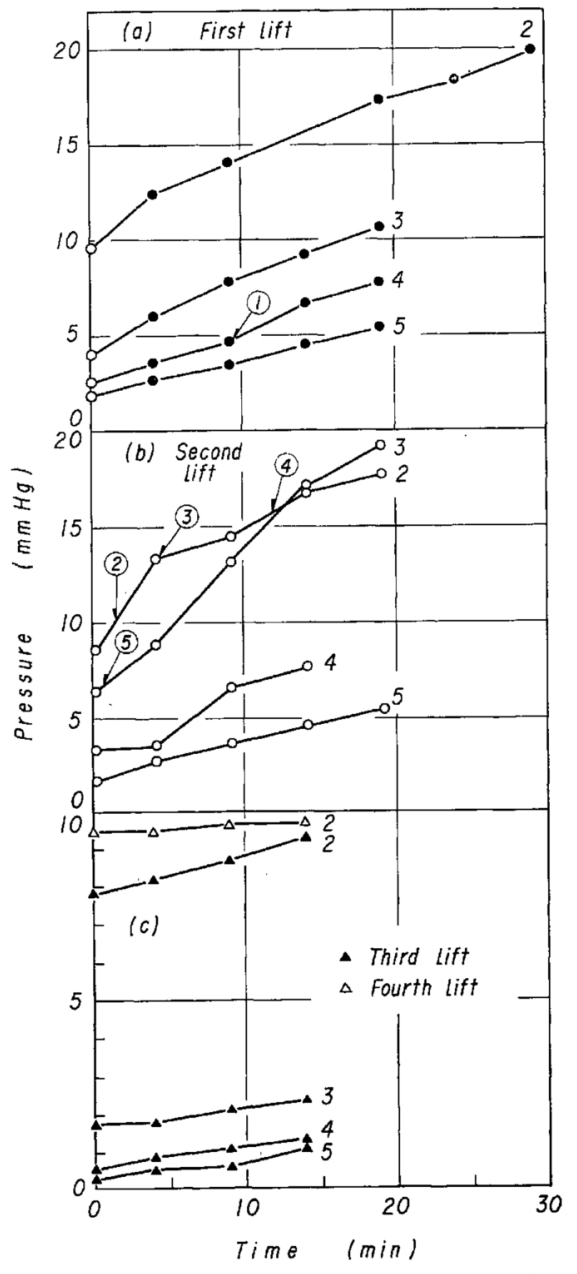

Fig. 5 Change of pressure with time (Repeated lift, Run 12). Numbers refer to the numbers of connected vacuum reservior tank.

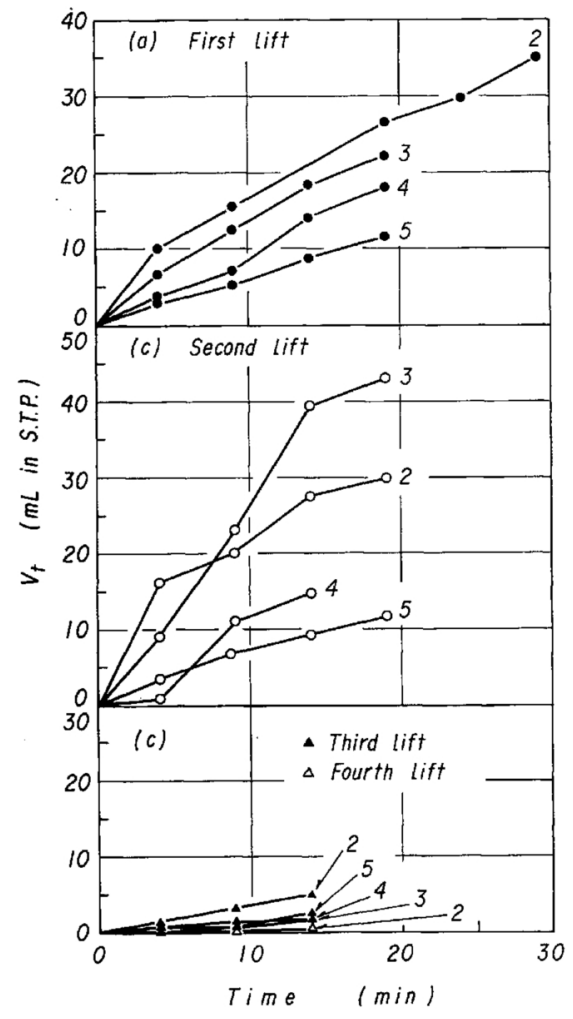

Fig. 6 Calculated volume of liberated $\mathrm{SO}_{2}$ gas with time (Run 12). Numbers refer to the numbers of connected vacuum reservior tank.
As a first approximation, the rate of degassing follows the first order kinetics as shown in Fig. 7, when the bubbling is negligible. The apparent rate constant $k$ is given by

$$
\log \frac{V_{e}-V_{t}}{V_{e}}=-k t
$$

where $V_{e}$ is the apparent total gas volume liberated during a step of connection with a tank, $V_{t}$ is the volume at the time $t$, and $k$ is the apparent rate constant, the values of which are listed in Table 1 .

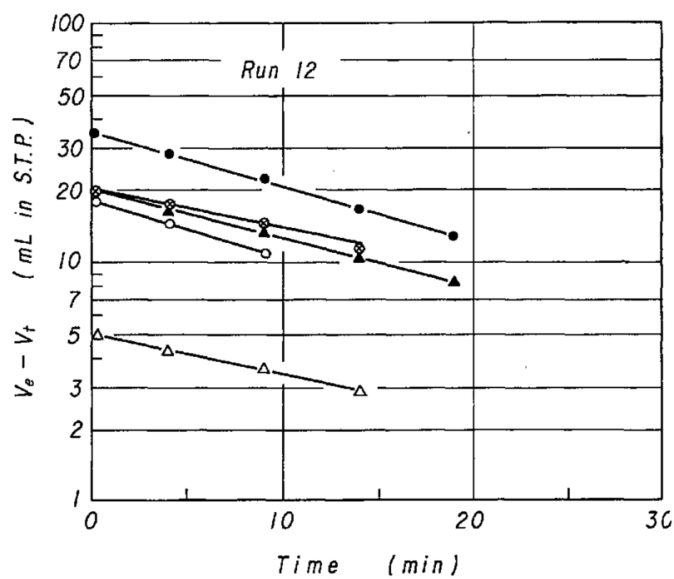

\begin{tabular}{c|c|c|c}
\hline Mark & $\begin{array}{c}\text { Repetition } \\
\text { of lift }\end{array}$ & $\begin{array}{c}\text { No. of a connected } \\
\text { vacuum tank }\end{array}$ & $V_{e}(\mathrm{~mL})$ \\
\hline- & $1 \mathrm{st}$ & No.3 & 35 \\
0 & $1 \mathrm{st}$ & No.4 & 18 \\
$\otimes$ & 1 st & No.5 & 20 \\
$\Delta$ & $2 \mathrm{nd}$ & No.5 & 20 \\
$\Delta$ & 3 rd & No.4 & 5
\end{tabular}

Fig. 7 Variation of liberated gas volume with time represented in the first order kinetics (Repeated lift).

Table 1 Typical apparent rate constants $(k)$ represented in the first order kinetics.

\begin{tabular}{|c|c|c|c|}
\hline Run & $\begin{array}{l}\text { Repetition } \\
\text { of lift }\end{array}$ & $\begin{array}{l}\text { No. of a connected } \\
\text { vacuum tank }\end{array}$ & $\left(\sec ^{-1}\right)$ \\
\hline 5 & 1 st & $\begin{array}{l}2 \\
3 \\
4\end{array}$ & $\begin{array}{l}6.41 \times 10^{-4} \\
5.25 \times 10^{-4} \\
6.88 \times 10^{-4}\end{array}$ \\
\hline 6 & 1 st & All & $2.07 \times 10^{-4}$ \\
\hline 8 & 1 st & $\begin{array}{l}3 \\
4 \\
5\end{array}$ & $\begin{array}{l}4.02 \times 10^{-4} \\
2.77 \times 10^{-4} \\
4.81 \times 10^{-4}\end{array}$ \\
\hline \multirow{3}{*}{12} & 1 st & $\begin{array}{l}3 \\
4 \\
5\end{array}$ & $\begin{array}{l}8.65 \times 10^{-4} \\
9.23 \times 10^{-4} \\
6.19 \times 10^{-4}\end{array}$ \\
\hline & $2 \mathrm{nd}$ & 5 & $7.62 \times 10^{-4}$ \\
\hline & $3 \mathrm{rd}$ & 4 & $6.40 \times 10^{-4}$ \\
\hline
\end{tabular}

\section{(2) Continuous measurement of oxygen} concentration

The variation of oxygen potential is shown in Fig. 8, together with the pressure change in the vessel. A large potential drop which suggests the increase of oxygen concentration takes place at the moment when 


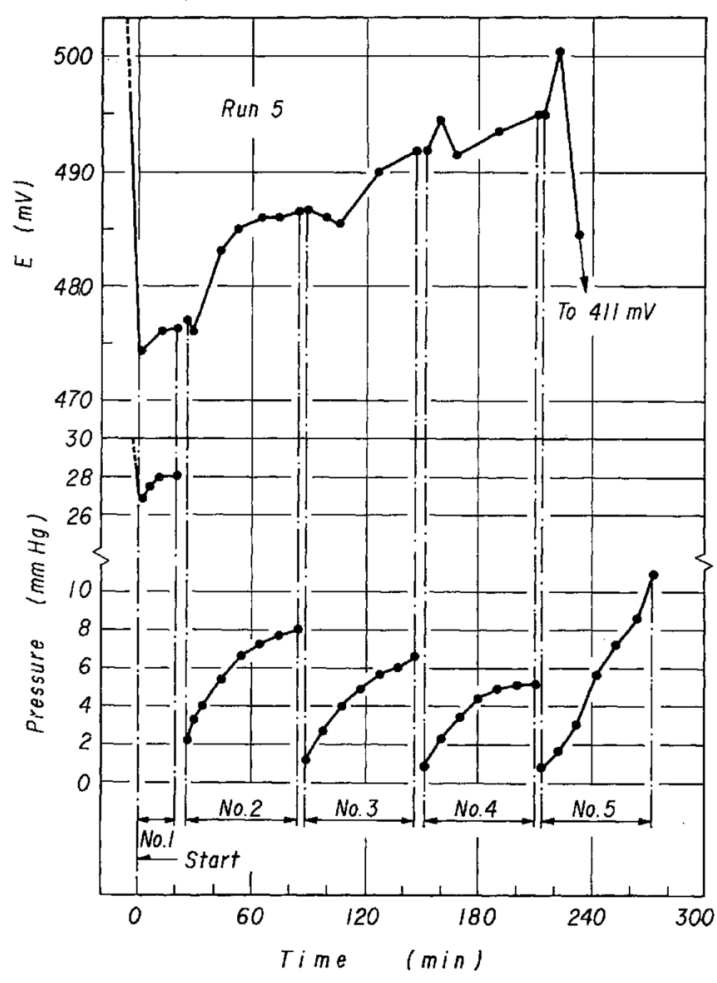

Fig. 8 Variation of oxygen potential refering to the concurrent pressure change. Numbers refer to the numbers of connected vacuum reservior tank.

the run starts and the melt rises to touch the electrodes, followed by a stepwise elevation of the potential in correspondence to the connections with a fresh vacuum tank. The abrupt fall of potential in the final step (connected with tank No. 5) is induced by violent bubbling.

\section{(3) Detection of bubble formation}

Examples of the recorded wave of attenuating vibration due to the burst of bubbles are shown in Fig. 9. The times when the vibration was recorded are marked by arrows with numbers in Fig. 5 . The volume of bubbles at the respective reduced pressures and the experimental temperature are estimated as $50 \sim 80 \mathrm{~mL}$ for waves of moderate amplitude.

\section{(4) Analytical values}

Experiments of total 15 runs with different initial concentrations of oxygen, sulphur, and some impurities were carried out as listed in Table 2. As for the final contents of oxygen and sulphur in refined copper, data are plotted in a diagram of the $\mathrm{O}-\mathrm{S}$ system which is presented in the later section.

An example of the variation of concentrations of impurities, $\mathrm{Pb}$ and $\mathrm{As}$, as a function of the distance from the surface of lifted copper is shown in Fig. 10, together with the shape of the solidified copper. An outstanding abnormality of both concentration curves is that the impurity concentration determined exceeds the level of the initial concentration to a great extent within the surface layer of a few $\mathrm{cm}$ 's of the solid. This abnormal tendency has been found in all cases where the refined copper was solidified as lifted in the vacuum vessel. Therefore, it is concluded that the

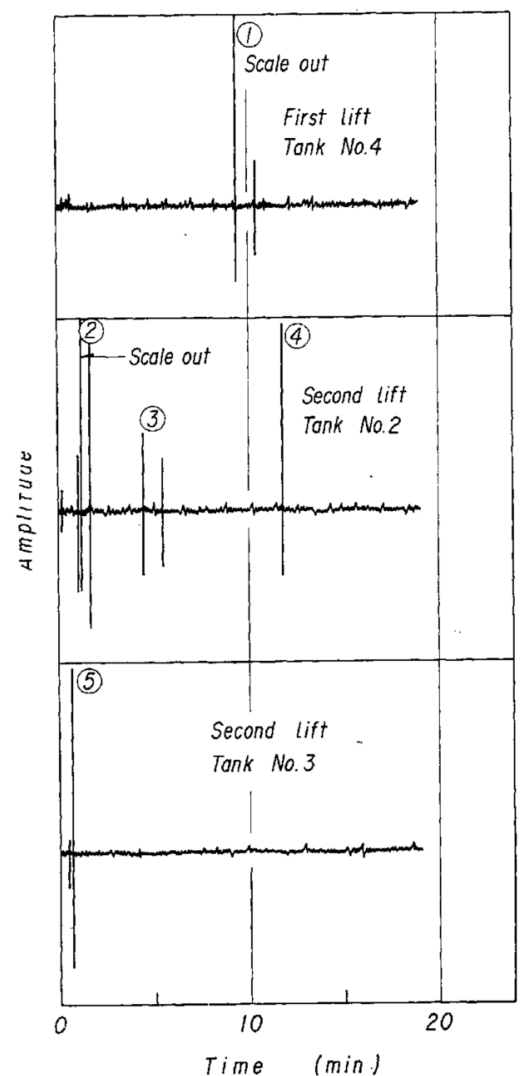

Fig. 9 Recorded vibration waves due to burst of bubbles (Run 12). Numbers : See Fig. 5.

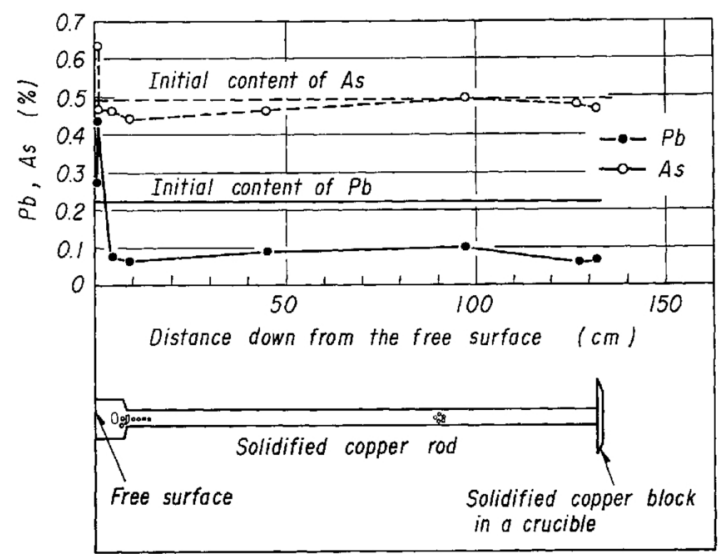

Fig.10 Impurity distributions in a solidified copper rod.

abnormality comes from the "back absorption", that is, an impurity vaporized from the lifted melt and condensed inside the cooling part of the vessel is absorbed again in the copper during the course of cooling for about 1 hour to a temperature $\left(700^{\circ} \mathrm{C}\right)$ where the melt is completely solidified and the diffusion in the solid is negligible. Except the abnormal high concentration, the average values are listed in Table 2.

In a solidified rod of copper two porous portions were found at around 10 and $90 \mathrm{~cm}$ from the surface, both of which were the portions at which the temperature lowered at last compared with the other portions. The formation of the porous portions might be attributed to the shrinkage of solidified copper, because a copper rod of $1.3 \mathrm{~m}$ changes the length to an extent of $26 \mathrm{~mm}$ for a temperature difference of $1000^{\circ} \mathrm{C}$. Before 
Table 2 Experimental data and concentrations before and after the vacuum lift.

\begin{tabular}{|c|c|c|c|c|c|c|c|c|c|c|c|c|c|c|c|c|c|c|}
\hline \multirow{2}{*}{ Run } & \multicolumn{5}{|c|}{ Initial content } & \multirow{2}{*}{$\begin{array}{c}\text { Repetition } \\
\text { of lift } \\
\text { (times) }\end{array}$} & \multicolumn{2}{|c|}{$\begin{array}{l}\text { Duration time } \\
\text { (min) }\end{array}$} & \multirow{2}{*}{$\begin{array}{c}\text { Minimum } \\
\text { pressure } \\
(\mathrm{mmHg})\end{array}$} & \multicolumn{5}{|c|}{$\begin{array}{l}\text { Impurity content of refined copper } \\
\text { (Average values) }\end{array}$} & \multicolumn{3}{|c|}{$\begin{array}{c}\text { Fraction } \\
\text { of removal } \\
(\%)\end{array}$} & \multirow{2}{*}{$\begin{array}{l}\text { Remark } \\
\text { in } \\
\text { Fig. } 10\end{array}$} \\
\hline & $\% 0$ & $\% \mathrm{~S}$ & $\% \mathrm{Sb}$ & $\% \mathrm{~Pb}$ & $\%$ As & & $<10$ & $\operatorname{ming}_{\text {ma }}$ & & $\% 0$ & $\% \mathrm{~S}$ & $\% \mathrm{Sb}$ & $\% \mathrm{~Pb}$ & $\%$ As & $\mathrm{Sb}$ & $\mathrm{Pb}$ & As & \\
\hline 1 & 0.150 & 0.090 & - & - & - & 1 & 270 & 3.5 & 0.6 & $0.115 *$ & $0.055^{*}$ & - & - & - & - & - & - & \\
\hline $\begin{array}{l}1 \\
2\end{array}$ & 0.260 & 0.170 & - & - & - & 1 & 280 & 11 & 0.5 & $0.210 *$ & $0.120 *$ & - & - & - & - & - & - & \\
\hline 3 & 0.200 & 0.100 & 0.430 & - & - & 1 & 24,0 & 180 & 0.02 & $0.178^{*}$ & $0.078 *$ & 0.250 & - & - & 42 & - & - & \\
\hline 4 & 0.260 & 0.170 & 0.450 & - & - & 1 & 260 & 8 & 0.6 & $0.218^{*}$ & $0.128^{*}$ & 0.130 & - & 一 & 71 & - & 一 & \\
\hline 5 & 0.076 & 0.064 & - & - & - & 1 & 240 & 5 & 0.7 & $0.045^{*}$ & $0.033^{*}$ & - & - & - & - & - & - & \\
\hline 6 & 0.034 & 0.037 & - & 一 & - & 1 & 144 & 46 & 0.3 & $0.021 *$ & $0.024 *$ & - & - & - & - & - & - & \\
\hline 7 & 0.089 & 0.056 & 0.460 & - & - & 1 & 130 & 16 & 0.3 & $0.081^{*}$ & $0.048^{*}$ & 0.330 & - & - & 28 & - & - & \\
\hline 8 & 0.620 & 0.028 & 0.420 & - & - & 1 & 112 & 13 & 0.5 & $0.602 *$ & $0.010^{*}$ & 0.350 & - & - & 20 & - & - & \\
\hline 9 & 0.061 & 0.100 & 0.350 & - & - & 1 & 116 & 7.5 & 0.4 & $0.049^{* *}$ & $0.088^{*}$ & 0.220 & - & - & 37 & - & - & \\
\hline 10 & 0.100 & 0.056 & - & 0.286 & - & 1 & 120 & 13 & 0.3 & $0.012 *$ & $0.088 *$ & - & 0.210 & - & - & 27 & - & \\
\hline 11 & 0.081 & 0.033 & - & - & 0.390 & 1 & 120 & 45 & 0. & $0.075^{*}$ & $0.027^{*}$ & - & - & 0.340 & - & - & 13 & \\
\hline 12 & 0.130 & 0.107 & - & 0.246 & - & 4 & 172 & 18.5 & 0.3 & 0.030 & 0.006 & - & 0.170 & - & - & 31 & - & \\
\hline 13 & 0.210 & 0.050 & - & 0.220 & 0.490 & 3 & 150 & 12 & 0.4 & 0.160 & 0.005 & - & 0.080 & 0.460 & - & 64 & 6 & 0 \\
\hline 14 & 0.100 & 0.063 & - & 0.208 & 0.428 & 6 & 50 & 0 & 8.0 & 0.056 & 0.021 & - & 0.150 & 0.400 & - & 28 & 7 & \\
\hline 15 & 0.110 & 0.021 & - & - & - & 4 & 150 & 12 & 0.7 & 0.100 & 0.013 & - & - & - & - & - & - & \\
\hline
\end{tabular}

* : Values calculated from the pressure change in vacuum tanks

starting this experiment, an attempt was made to obtain a refined copper by cooling as lifted, but it encountered with great difficulties owing to the unexpected phenomena described above.

\section{Discussion}

The Cu-S-O system has been studied in detail under equilibrium conditions by several workers ${ }^{(3) \sim(5)}$. The simplest relation representing the equilibrium between the dissolved oxygen, $\underline{\mathrm{O}}$, and sulphur, $\underline{\mathrm{S}}$, in molten copper and a gas phase containing $\mathrm{SO}_{2}$ is represented by

$$
\begin{aligned}
& \mathrm{SO}_{2}(\mathrm{~g})=\underline{\mathrm{S}}+2 \underline{\mathrm{O}} \\
& K=\frac{(\underline{\mathrm{S}})(\underline{\mathrm{O}})^{2}}{P_{\mathrm{SO}_{2}}}
\end{aligned}
$$

where $K$ is a temperature-dependent constant. When $\underline{\mathrm{O}}$ and $\underline{\mathrm{S}}$ are represented in wt $\%$ as $(\% \mathrm{O})$ and $(\% \mathrm{~S})$, the $K$ in eq. (4) is not a constant for high concentrations of dissolved oxygen and sulphur.

Johannsen and Kuxmann ${ }^{(3)}$ pointed out that $\underline{\mathrm{S}}$ and $\underline{0}$ form molecular $\mathrm{SO}_{2}$ in the melt that is in equilibrium with $\mathrm{SO}_{2}$ in the gas phase and obtained the following equation :

$$
K_{1}=\frac{\left[(\% \mathrm{~S})-1 / 2 K_{2} P_{\mathrm{SO}_{2}}\right]\left[(\% \mathrm{O})-1 / 2 K_{2} P_{\mathrm{SO}_{2}}\right]^{2}}{P_{\mathrm{SO}_{2}}}
$$

where $K_{1}$ is a constant and $K_{2}$ is a constant associated with the dissolved molecular $\mathrm{SO}_{2}, \underline{\mathrm{SO}}_{2}$, as represented by

$$
\begin{array}{r}
\mathrm{SO}_{2}(\mathrm{~g})=\underline{\mathrm{SO}}_{2} \\
K_{2}=\frac{\left(\% \mathrm{SO}_{2}\right)}{P_{\mathrm{SO}_{2}}}
\end{array}
$$

and the values are $1.6 \times 10^{-5}$ and $3.0 \times 10^{-5}$ at $1150^{\circ} \mathrm{C}$ for $K_{1}$ and $K_{2}$, respectively.

Sano and Sakao ${ }^{(4)}$ studied the change of activities of $\underline{\mathbf{O}}$ and $\underline{\mathrm{S}}$ in molten copper that is due to the presence of

(3) F. Johannsen and U. Kuxmann : Erzmetall, 2 (1955), 45.

(4) K. Sano and H. Sakao : J. Japan Inst. Metals, $19(1955), 655$.

(5) M. Izawa : J. Min. Met. Inst. Japan, 58 (1942), 45.
$\underline{\mathrm{S}}$ and $\underline{\mathrm{O}}$, respectively. From their result the following equations at $1200^{\circ} \mathrm{C}$ are derived.

$$
\begin{aligned}
\log P_{\mathrm{SO}_{2}}= & 2 \log (\% \mathrm{O})-0.752(\% \mathrm{O})+\log (\% \mathrm{~S}) \\
& -0.521(\% \mathrm{~S})+2.001 \\
\log P_{\mathrm{O}_{2}}= & 2 \log (\% \mathrm{O})-0.4227(\% \mathrm{O}) \\
& -0.3294(\% \mathrm{~S})-4.195 \\
\log P_{\mathrm{S}_{2}}= & 2 \log (\% \mathrm{~S})-0.382(\% \mathrm{~S}) \\
& -0.658(\% \mathrm{O})-5.756
\end{aligned}
$$

The functional relation between $(\% 0)$ and $(\% \mathrm{~S})$ in molten copper and the partial pressure of $\mathrm{SO}_{2}, P_{\mathrm{SO}_{2}}$, is illustrated in Fig. 11 for different $P_{\mathrm{SO}_{2}}$ ranging from 760 to $1 \mathrm{mmHg}$.

At high concentrations of sulphur, the upper limit of solubility of sulphur in molten copper at $1200^{\circ} \mathrm{C}$ is about $1.0 \%{ }^{(6)}$, at which the melt is in equilibrium with $\mathrm{Cu}_{2} \mathrm{~S}$ (about $20 \% \mathrm{~S}$ ) beyond the immissible gap. At high concentrations of oxygen, the upper limit of solubility of oxygen is about $1.5 \%{ }^{(6)(7)}$, beyond which the primary solid phase of $\mathrm{Cu}_{2} \mathrm{O}$ appears in the melt. In the $\mathrm{Cu}-\mathrm{S}-\mathrm{O}$ system the vertical line for the solubility limit of sulphur and the horizontal line for that of oxygen should deviate rightwards for high $\underline{Q}$ and upwards for high $\underline{\mathrm{S}}$, respectively, owing to the interaction between dissolved species as shown in Fig. 11 . These deviations are, however, not a serious problem in the present study, since the deviations take place at a very high partial pressure of $\mathrm{SO}_{2}$.

The simple relation represented by eq. (4) should be a straight line with a slope of $-1 / 2$ in Fig. 11 . This is true in the low concentration region of both $(\% \mathrm{~S})$ and $(\% 0)$. As is obvious from eqs. (5) and (8), the lines representing eq. (4) are no longer linear for high concentrations of $(\% \mathrm{~S})$ and/or $(\% 0)$.

A point corresponding to the blister copper produced in the copper making stage in a converter (the closed circle) is the intersecting point between the upper limit of solubility of sulphur (the vertical line) and the

(6) A. Yazawa and T. Azakami : Bull. Res. Inst. Min. Dress. Met. Tohoku Univ. Japan, $23(1967), 67$.

(7) M. Hansen : Constitution of Binary Alloys, McGraw-Hill, 2 nd ed., New York, p. 604. 


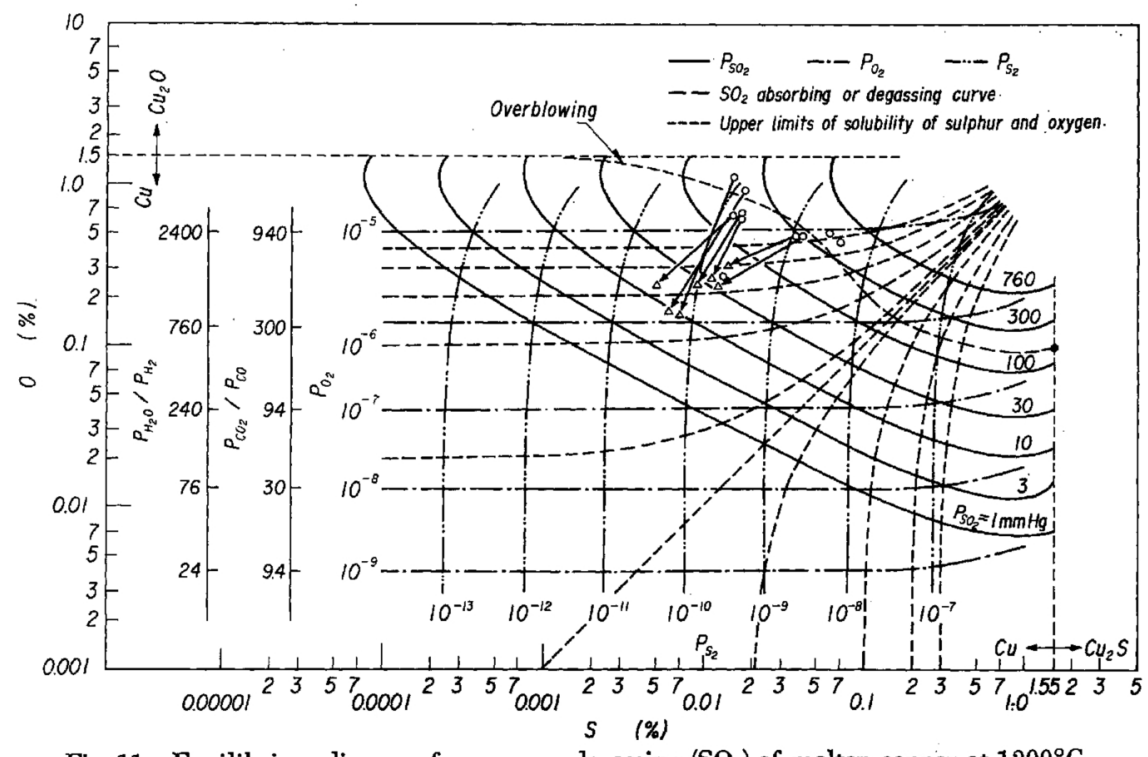

Fig. 11 Equilibrium diagram for vacuum degassing $\left(\mathrm{SO}_{2}\right)$ of molten copper at $1200^{\circ} \mathrm{C}$.

inclined curve corresponding to $P_{\mathrm{SO}_{2}}=152 \mathrm{mmHg}$ in Fig. 11. After the cuprous sulphide phase is completely converted into blister copper, the point travels along the curve for $P_{\mathrm{SO}_{2}}=152 \mathrm{mmHg}$ as the melt is overblown.

When the sulphur concentration in the melt decreases to a certain critical value, a kinetic factor of the oxidation reaction overcomes the thermodynamic equilibrium. Several investigations on decarburization of iron melt by oxygen blowing ${ }^{(8)}$ emphasize the variation of reaction kinetics at a concentration of around 0.1 to $0.2 \%$ $\mathrm{C}$ : at higher concentrations than the critical value the oxidation follows the zerø-th order kinetics where the rate is determined by the flow rate of oxygen, while at lower concentrations the oxidation proceeds approximately in the first order kinetics. It seems reasonable to consider that such the variation of reaction kinetics also takes place in the present case of copper overblowing.

Open circles in Fig. 11 are sulphur and oxygen contents of overblown blister copper reported by several smelters in Japan, and the curve representing these circles deviates from the isobar for $P_{\mathrm{SO}_{2}}=152 \mathrm{mmHg}$ at around $0.15 \% \mathrm{~S}$, where supposedly the reaction varies from the oxidation of sulphur in the nearly equilibrium process to the oxidation of copper which results in a rapid increase of oxygen content, finally leading to an asymptote to the upper limit of solubility of oxygen.

By the refining operation subsequent to the overblowing, oxidized copper is reduced by a suitable reductant. Sulphur and oxygen contents of refined blister copper are shown by open triangles each with an arrow indicating the change during the refining operation. It is seen in Fig. 11 that there are two kinds with regard to the direction of arrows: one is rather vertical suggesting that the decrease of oxygen content takes place without a large decrease in sulphur content, and the other is rather horizontal suggesting a simultaneous decrease in oxygen and sulphur contents.

(8) D. A. Dukelow and G.C. Smith : Trans. Met. Soc. AIME, 230 (1964), 71 .
The overblown copper is strongly reduced by pulverized coal, ammonia gas, or natural gas in the case of the former, while it is reduced indirectly by heavy oil in the case of the latter.

Oxygen and sulphur contents calculated from the pressure change of vacuum tanks and those determined by analysis of the solidified samples are shown by the open and closed circles in Fig. 12, respectively. Only 4 reliable values (average values) were obtained as for the analysis of oxygen, because it was very difficult to cut a small copper rod into a defectless dice available for the vacuum fusion method of oxygen.

Figure 12 reveals that values determined by analysis are in general lower than those calculated from the pressure change. In the case of run 12 the initial concentrations of oxygen and sulphur, 0.130 and $0.107 \%$,

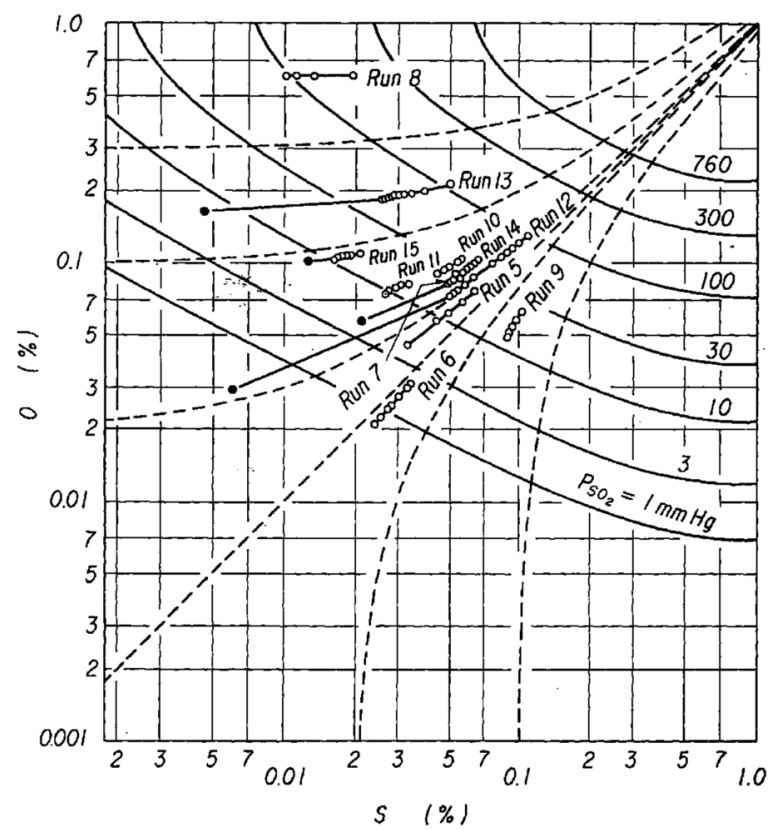

Fig. 12 Experimental results of oxygen and sulphur contents shown on the $(\% \mathbf{O}) \sim(\% \mathrm{~S})$ diagram. Open circles and closed circles represent oxygen and sulphur contents calculated from the pressure change of vacuum tanks and those determined by analysis of solidified copper samples, respectively. 
respectively, decreased to $0.030 \%$ for oxygen and 0.006 $\%$ for sulphur, after vacuum lifts of 4 times each at about $2 \mathrm{mmHg}$ (see Fig. 5).

It has been finally concluded that experiments of the vacuum lift process with such a small apparatus as described here is rather difficult to obtain a conclusive result, owing to

(1) blow up of the melt in the vacuum vessel at the start of vacuum lift,

(2) most of dice cut from a small solidified copper rod have defects which result in an abnormally high oxygen content, when the content is determined by the vacuum fusion method,

(3) solidification of the melt as lifted to get refined copper is not a suitable method due to back-absorption of impurities,

(4) dissolution of oxygen at the surface of the melt in a crucible should affect both the liberation of $\mathrm{SO}_{2}$ and the final content of oxygen.

Among these difficulties the blow-up of the melt is a most serious problem. Several experiments ended in failure owing to the blow-up due to violent bubbling. The experimental data obtained under a condition of gentle bubbling are, on the other hand, have a limit to put the vacuum lift process to practice. Violent bubbling in a vacuum vessel causes strong agitations in the lifted content, and this is rather favorable for accelerated elimination of impurities. Therefore, further studies have been carried out using a sample of about $6 \mathrm{~kg}$ and a vacuum vessel of $4 \mathrm{~cm} \mathrm{ID,} \mathrm{and} \mathrm{the}$ results will be reported elsewhere.

\section{Conclusion}

A vacuum lift apparatus consisting of a vacuum lift part and a vacuum system with five vacuum reservior tanks with the capacity of $2.5 \mathrm{~L}$ was made and the concurrent elimination of oxygen, sulphur, arsenic, antimony, and lead in synthetic blister copper samples was studied using a copper sample of $600 \mathrm{~g}$ under reduced pressures of a few $\mathrm{mmHg}$ at $1200^{\circ} \mathrm{C}$.
A transparent quartz tube of $1.6 \mathrm{~cm}$ ID was used as the vacuum vessel, but it seemed that the ID was too small for the violent bubbling of $\mathrm{SO}_{2}$ gas at the start of vacuum lift, when the initial concentrations of oxygen and sulphur were higher than $0.2 \%$.

The volume of liberated $\mathrm{SO}_{2}$ gas during the vacuum lift process was calculated from the pressure change of vacuum tanks connected in turn with the vacuum vessel.

The decrease of oxygen concentration in the lifted copper was continuously measured by means of an oxygen concentration cell using a calcia stabilized zirconia which was immersed in the lifted copper. The number of bubbles generated in the lifted copper was counted by the aid of a crystal microphone attached to the inside of the top of the vacuum vessel. The barometric vibration due to the burst of bubbles was picked up by the microphone and recorded.

A synthetic blister copper containing initial contents of $0.130 \%$ oxygen and $0.107 \%$ sulphur was refined to a copper containing $0.030 \%$ oxygen and $0.006 \% \mathrm{~S}$ after vacuum lifts of 4 times at an average pressure of about $2 \mathrm{mmHg}$. Studies on the removal of impurities revealed that 40 to $70 \%$ of antimony, 30 to $60 \%$ of lead, and about $10 \%$ of arsenic can be eliminated for the initial contents of $0.4,0.25$, and $0.4 \%$, respectively.

The present process of overblowing of blister copper in a converter and subsequent reduction to refined blister copper in a refining furnace was discussed in terms of an equilibrium diagram representing the functional relation among dissolved oxygen and sulphur in molten copper and the partial pressure of $\mathrm{SO}_{2}$ in the gaseous phase, and a comparison with the vacuum refining process was presented. Some suggestions for further experiments were also given.

\section{Acknowledgment}

The authors are indebted to the Ashio Smelter for chemical analysis of arsenic, antimony and lead in copper samples. 